\title{
Response to letter: "Stereotactic biopsies of brainstem lesions: dilemma on the best trajectory"
}

\author{
Amer Jaradat $^{1}\left({ }^{10} \cdot\right.$ Claudio Pollo $^{2}$ \\ Received: 15 May 2021 / Accepted: 18 June 2021 / Published online: 4 August 2021 \\ (C) The Author(s), under exclusive licence to Springer-Verlag GmbH Austria, part of Springer Nature 2021
}

\section{Dear Editor}

We thank Mathon et al. for their insightful contribution regarding the efficacy, safety, and choice of trajectory of brainstem lesions stereotactic biopsies.

In their letter, Mathon et al. showed that supratentorial transfrontal approach was the predictor of post-biopsy symptomatic complications, although biopsy trajectory could not be identified as an independent predictor of biopsy-related mortality in a previous study on 1500 consecutive stereotactic biopsies [6]. Other parameters (patient population, nature of the biopsied lesions, or different anaesthesia protocol) might still have an impact on this observation.

On the other side, case series of brainstem stereotactic biopsies performed through a supratentorial transfrontal approach seemed not to show an increased complication rate $[1,5]$. Nevertheless, as discussed in our publication [2], we also believe that crossing the entire brainstem or part of it to reach a lesion has intrinsically more complication rate, as, in our experience, (transient) neurological deficits may appear without bleeding and not necessarily at the biopsy location. We also favor a transcerebellar transpeduncular approach as it is the shortest approach and avoids crossing the brainstem, as long as the lesion can be reached and biopsied.

We also agree that the number of collected tissue samples has to be limited as much as possible to avoid complications like bleeding and/or neurological deficits. Thus, beyond the use of intraoperative diagnostic evaluation, the use of fluorescent agents (e.g., 5-ALA), especially for high-grade glioma [4] and lymphoma [3] patients, is certainly helpful in

This article is part of the Topical Collection on Brain Tumors

Amer Jaradat

Amerjaradatsh@gmail.com

1 Department of Neurosciences, Jordan University of Science and Technology, Ar Ramtha 3030, Ar-Ramtha, Jordan

2 Department of Neurosurgery, Inselspital, University Hospital Bern, and University of Bern, 3010 Bern, Switzerland this respect. In our experience, the availability of an experienced neuropathologist is also mandatory to obviate the need for higher numbers of specimens.

\section{References}

1. Cheng G, Yu X, Zhao H, Cao W, Li H, Li Q, Li Z, Yin F, Liu R, Zhang J (2020) Complications of stereotactic biopsy of lesions in the sellar region, pineal gland, and brainstem: a retrospective, single-center study. Medicine (Baltimore) 99(8):e18572

2. Jaradat A, Nowacki A, Fichtner J, Schlaeppi J-A, Pollo C (2021) Stereotactic biopsies of brainstem lesions: which approach? Acta Neurochir. https://doi.org/10.1007/s00701-021-04733-2

3. Kiesel B, Millesi M, Woehrer A et al (2018) 5-ALA-induced fluorescence as a marker for diagnostic tissue in stereotactic biopsies of intracranial lymphomas: experience in 41 patients. Neurosurg Focus 44(6):E7

4. Millesi M, Kiesel B, Wöhrer A, Mercea PA, Bissolo M, Roetzer T, Wolfsberger S, Furtner J, Knosp E, Widhalm G (2020) Is intraoperative pathology needed if 5-aminolevulinic- acid-induced tissue fluorescence is found in stereotactic brain tumor biopsy? Neurosurgery 86(3):366-373

5. Quick-Weller J, Lescher S, Bruder M, Dinc N, Behmanesh B, Seifert V, Weise L, Marquardt G (2016) Stereotactic biopsy of brainstem lesions: 21 years experiences of a single center. J Neurooncol 129(2):243-250

6. Riche M, Amelot A, Peyre M, Capelle L, Carpentier A, Mathon B (2020) Complications after framebasedstereotactic brain biopsy: a systematic review. Neurosurg Rev. https://doi.org/10.1007/ s10143-019-01234-w

Publisher's note Springer Nature remains neutral with regard to jurisdictional claims in published maps and institutional affiliations. 